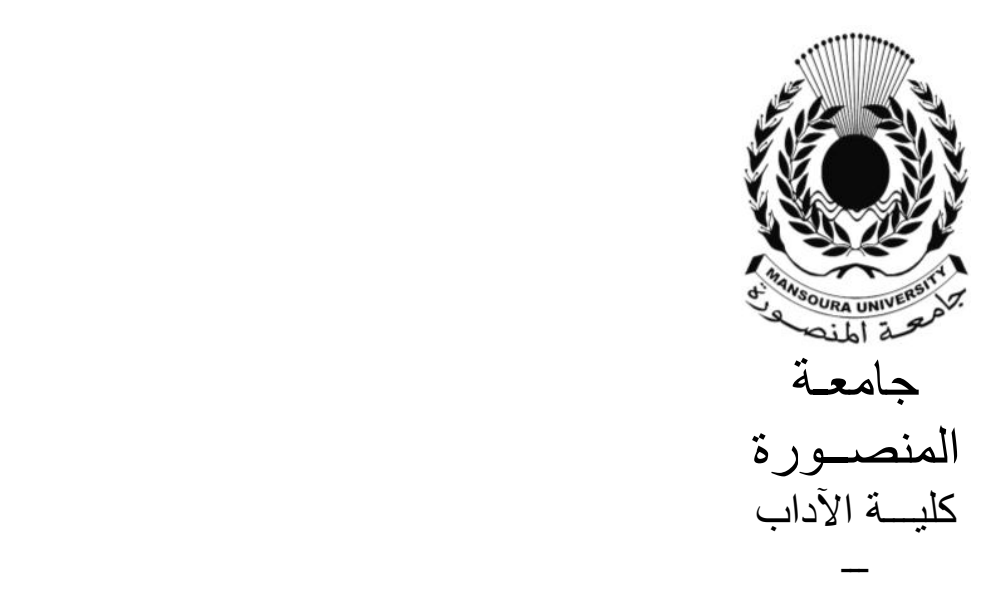

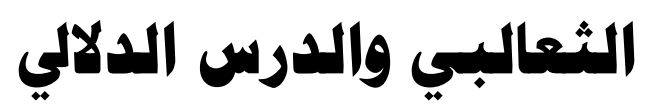

\author{
إعـــد/د

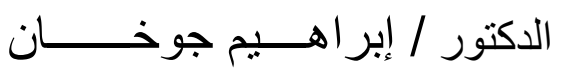 \\ قسم اللغة العربية

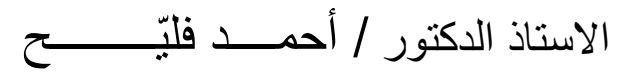 \\ جامعة جرش الم الش \\ رئيس قسم اللغة العربية \\ جامعة جرش
}

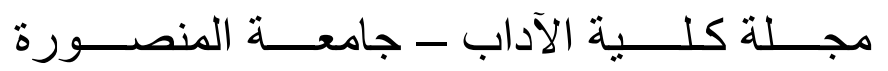

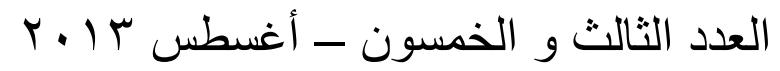




\section{الثعالبي والدرس الدلالي}

أ. د. أحمــــد فلـــــح

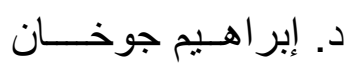

بسم الله والحمد لله، والصلاة والسلام على سيدنا محمد بن عبد الله.

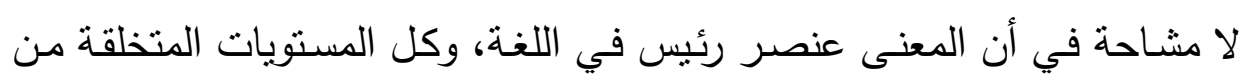

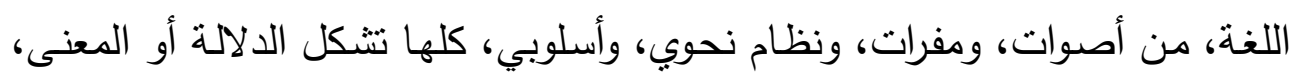

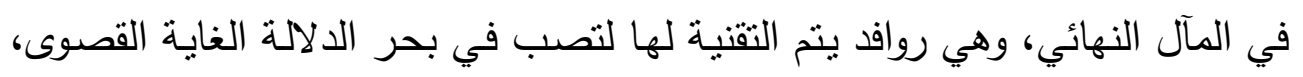
وأية دنظومة لغوية لا لتنوي على معنى مستجمع لا قيمة لها. ونمو علم الدلالة الحديث ونتثعب مقارياته المنهجية، جعله قطب الدوران في كل

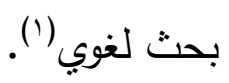

\section{والموئل المشتهر للمقاريات اللالية هو المعاجم.}

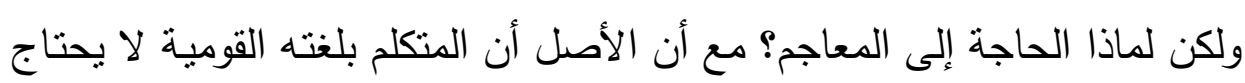

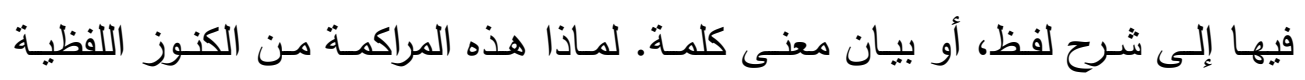

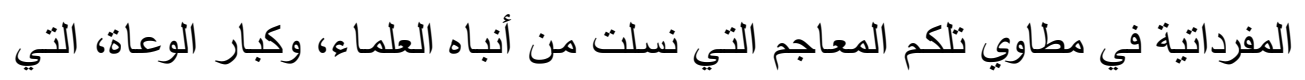

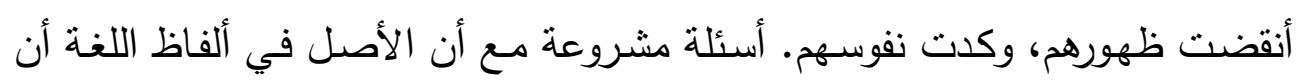

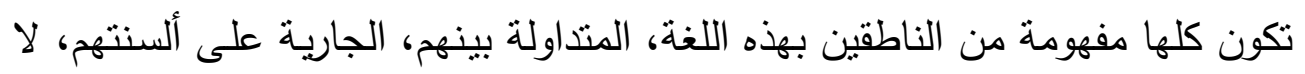

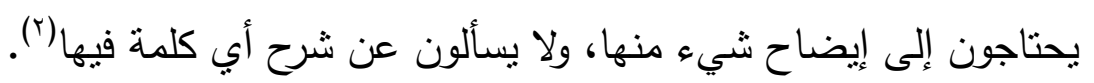

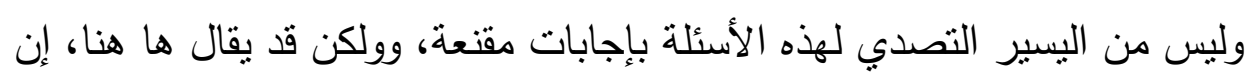

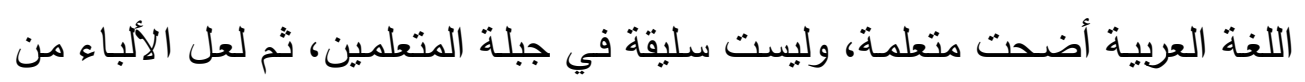

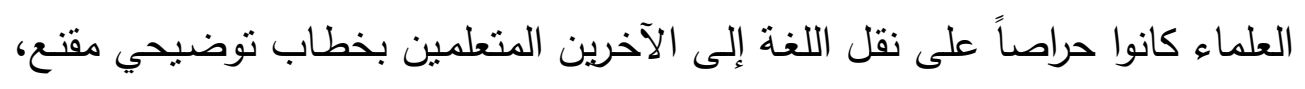

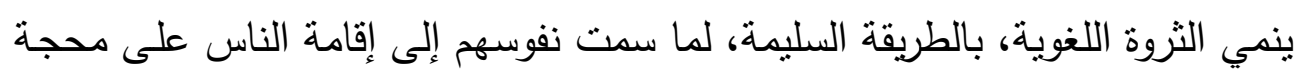


الفصحى، ومراكمة رصيد لغوي يسعف المتكلم والدتعلم، ويفضي إلى تتامي الأداء بوتائر لغوية سلسلة يمتح منها المتلقي ساعة يستفرغ أداء فكرياً معلوماً.

فالمعجم اللغوي حافظة لكنوز اللغنة، ورافعة للسوية العلمية، يفزع إليه العلماء بله

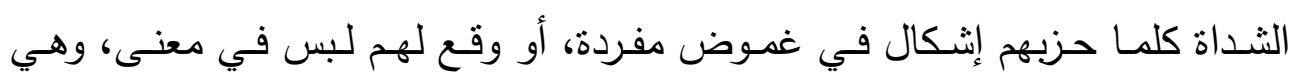
تستجمع منظومة من البصائر اللغوية في نواميس العربية وسننها. ولا مراء في أن الصناعة المعجمية العربية مرت في أطوار مشهودة إلى أن تتاهت

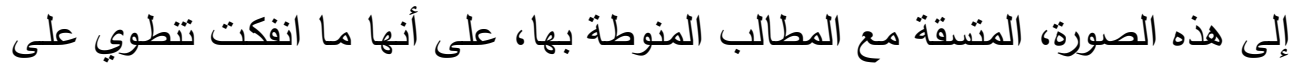
نقائص تتنظر من أهلها أن يشمروا للنهوض بالوفاء لهذه الرسالة.

ومن التتبع استظهرنا ثلاثة أطوار مرت بها صاعة المعجم العربي ومنها: أ. الرسائل اللغويـة التي تتمحور حول معانٍ بعينها، تورد لها جملة من الأسماء

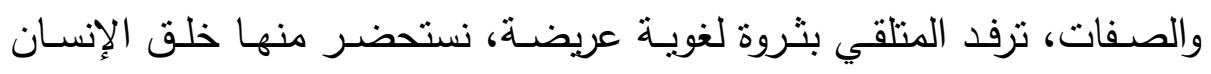

$$
\text { للأصمعي (ت • مآهـ). }
$$

وكتاب النبات لأبي حنيفة الدينوري (ت م9 آهـ).

$$
\text { وكتاب الخيل لقطرب (ت } 7 \text { • rهـ). }
$$

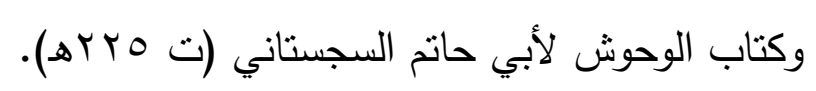

$$
\text { أسماء البئر وأسماء الخيل لابن الأعرابي (ت r r هـA). }
$$

وغيرها كثير ، فقد أخذ اللغويون، في هذه الحقبة يحصرون مادة اللغة العربية في

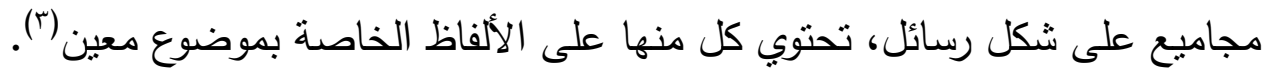
ومن الواضح أن الهدف من هذه الرسائل تعليمي، لأنه يقدم للمتأدبين الطرائق

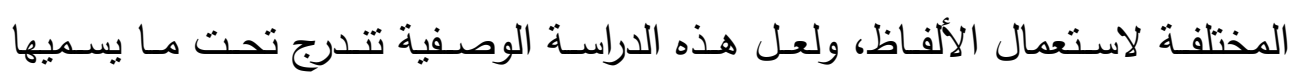


المحدثون الدراسـات الأسـلوبية(؛). وهو نمط مـن التلقي الإحيائي للغـة، يجذرها في نفوس القراء والمتلقين، ويمد فيها نسخ الحياة والانتشار . ب. وظهرت مصنفات أخرى جامعة لمادة اللغة، مرتبـة بحسب الموضوعات، وتعد تجديداً في هذه الصناعة لكونها خالفت ما مرد عليه العلماء في منهج الصناعة المعجمية والدرس الأسلوبي في ذللك الإبان، وتعد تجديداً في سنن هذه الصناعة ونواميسها ومنها: كتاب الألفاظ لابن السكيت (ت ع ع ك هـ). ولعله أقدم ما ألف على هذا الصعيد ومنها: مبادئ اللغة للإسكافي (ت اY؟sه) وحققه عالمان جليلان الأستاذ الدكتور يحيى عبابنة، والأستاذ الدكتور عبد القادر الخليل. ومنها: فقه اللغة وسر العربية لأبي منصور الثعالبي النيسابوري (ت و ؟ §ه) ثم المعجم الموضوعي الثـامل الموسوم بالمخصص لابن سيدة الأندلسي (ت م0^؛ـ) وبقع في سبعة عشر مجلداً. ولعله من أوفى المعاجم المعنوية بقسميها الرسائل اللغوية المقتصرة على طائفة من المعاني، أو الموسوعات اللغوية التي تعنى ببيان المفردات والألفاظ الموضوعة للمعاني (0).

وتتبع أهمية المعاجم المعنويـة أن المرء قد يخطر بباله معنى لا يجد لـه لفظاً أو كلمة تتاسبه، فينتجع هذه المعاجم المعنوية التي توفر له اللفظة المفصلة للمعنى الذي راود ذهنه فيجد ضالته في المعاجم الموضوعية الآتفة المرتبة على حسب الأفكار ، أو الموضـوعات، أو المعـاني، ومبلـغ الانتفـاع، وسـرعة التأتي تتبثت مـن ترتيب هاتيك المعجمات بما ييسر ويسرع الانتفاع. وهذا القسم من المعجمات يرجع إليه من يعرف معنى ويرغب في الوقوف على الألفاظ الموضوعة له(؟) كما أسلفنا. 
وهي على عكس النوع الآخر من المعجمات العربية، التي ترمي إلى شرح معاني المفردات.

وتتوقف مقاربتـا في هذه الورقة لدى مصنف مشتهر لمؤلف فذ هو الثغالبي

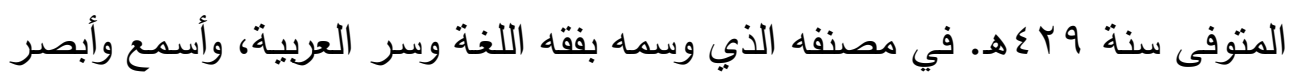
بالثعالبي ومصنفه.

وأسئلة هذه المقاربـة تشكل فضـاء لهذه القراءة ومنافذ لتجليته ومنهـا: مـن هو الثعالبي؟ وما أظهر تصانيفه؟ ومنهج الثعالبي.

لماذا سخى بنفسه عن كثرة الثواهد؟ ما هدف هذا المصنف وما صحة إدراجه في

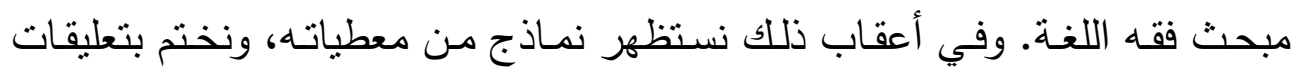

الثعالبي: هو عبد الملك بن محمد بن إسماعيل، أبو منصور الثعالبي النيسابوري كان واعية كثير الحفظ، لقب بجاحظ زمانه.

يجمع الدارسون على أنه ولا سنة خمسين وثلاث مئة وتوفي سنة تسع وعشرين

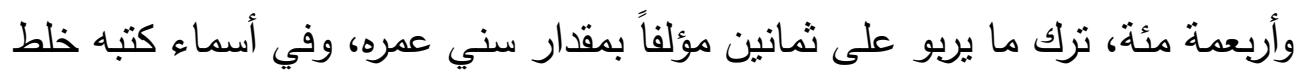
وتداخل، ورجع نظر ، وتقضي التمحيص والتدقيق.

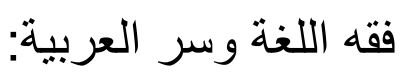
اصطنع الثعالبي، رحمه الله، اسم كتابه فقه اللغة، تعسفاً وتجاوزاً، فققه اللغة يفارقه

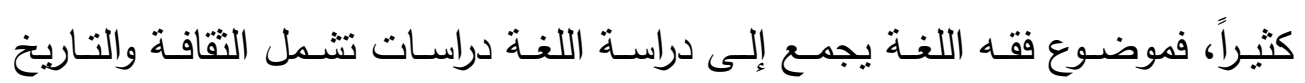

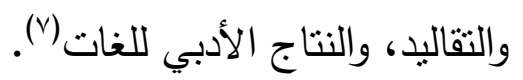

وفقه اللغة لأبي منصور الثعالبي معجم من المعاجم اللغوية رتبت فيه المادة ترتيباً

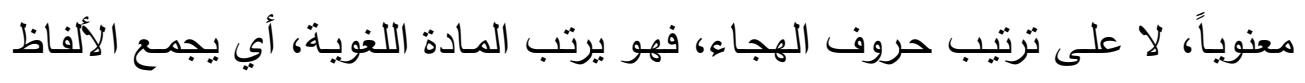


التي تستعمل في موضوع واحد، وفائدته لمن يعرف معنى من المعاني، ويتطلب فيه

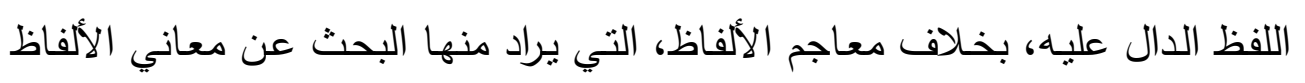
التي بريد الباحث تفسيرها.

فهو من نوع الكتب التي من شأنها أن تمد الكاتب بعبارات بليغة بيتعطلها في

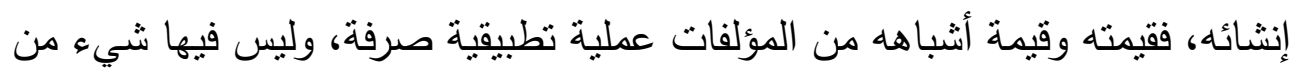
فقه اللغة (^). ويعد كتاب فقه اللغة وسر العربية نموذجاً في منهج متميز في صناعة المعاجم

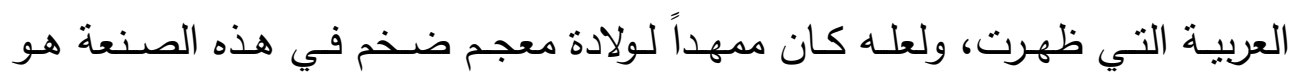

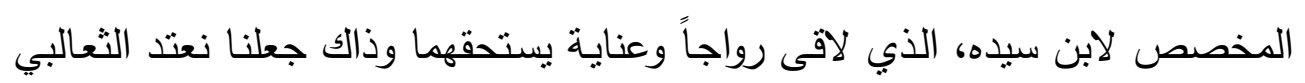

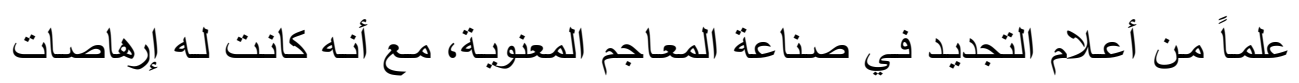
تقدمته إلا أنه شآها ومهذ لمن تبعه، وجلها كان وليد العيد العصر العباسي الذهبي.

\section{منهجه:}

استهل المؤلف هذا المعجم اللغوي المعنوي بمقدمة ضافية تمدح بها العربية فقال:

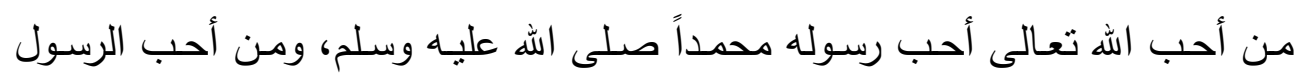

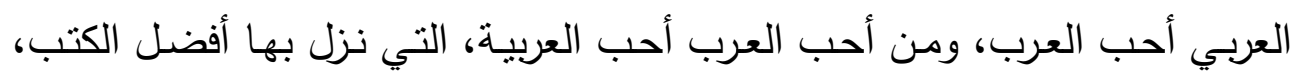

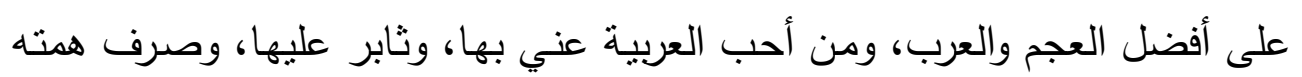
إليها(9). وانتقل عقيب ذلك إلى ثبت الأبواب بلغت عدتها ثلاثين باباً. والكتاب، كما هو معلوم، في قسمين: القسم الأول، وهو موضع درسنا، وسمه بفقه اللغة، وجعل الثاني باسم: سر العربية.

$$
\text { وقسم كل باب إلى فصول. }
$$


وجعل مستهل كل فصل سند الرواية، ومرجعيته، فلجوا معي أحد الأبواب والفصول المبثوثة في مطاويه، لنستجلي المعطيات الثزة التي استعجمعها المؤلف. الباب الأول في الكليات، قال: كل ما علاك فأظلك فهو سماء، وكل أرض مستوية فهي صعيد، وكل حاجز بين الثنيئن: فهو موبق، وكل بناء مربع فهو كعبة، وكل بناءٍ

$$
\text { عالٍ فهو صرح... وهلم جراً. }
$$

ثم ينتهي إلى الفصل الثاني في ذكر ضروب من الحيوان، ويشفعها بأسماء العلماء

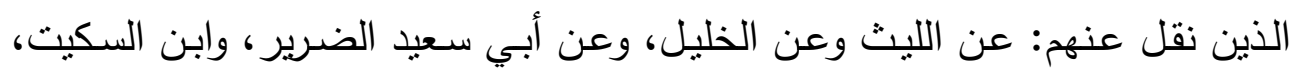

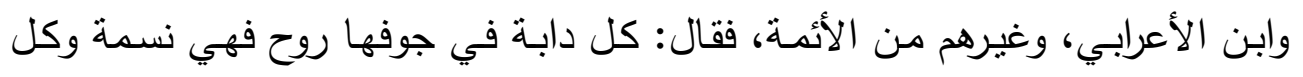
كريمة من النساء والإبل والخيل وغيرها فهي: عقيلة. والفصل الثالث من الكليات في النبات والثجر.

وسلسلة الرواة هي: عن الليث وعن الخليل، وعن ثعلب عن ابن الأعرابي، وعن

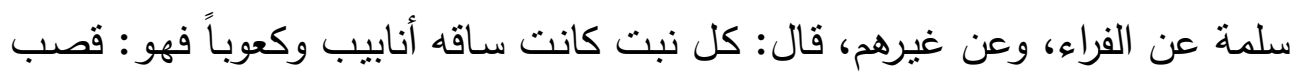

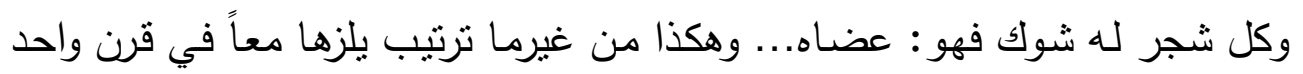
إلا جامع كلمة (كل)، ويحار المراجع كيف يجد ضالته فئه في هذه الأكوام. والفصل الرابع في الأمكنة، والخامس في الثياب، والسادس في الطعام والسابع في فنون مختلفة الترتيب. وكل فصل يبدأ بكلمة كل: كل ريح تهب بين ريحين فهي نكباء، كل ريح لا تحرك

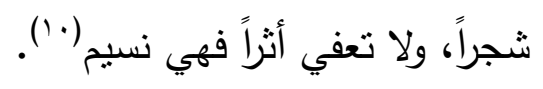
بيد أنه في الفصول الثامن والتاسع، والعاشر، والحادي عشر والثاني عشر، والثالث

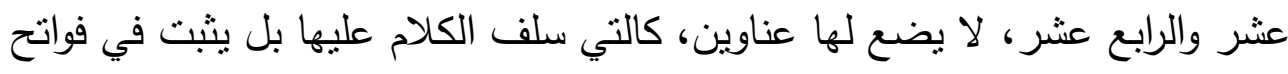


الفصل (عن) كأن يقول: عن أبي بكر الخوارزمي، عن ابن خالويه كل عطر مائع فهو ملاب، وكل عطر يابس فهو الكباء. وأحياناً يقول: عن الأئمة. كل شيء جاوز الحد فقد طغى. وفي الفصلين العاثـر والحادي عثر لا يبدأ بكلمة كل بل يقول: اقتمّ ما على كلى

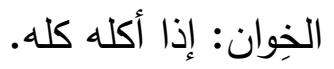

أو : ولد كل سبع جرو، وولد كل طائر فرخ، وغرة كل شيء أوله وفي الفصل الرابع عشر يستأنف قائلاً: الجم: الكثير من كل شيء، والعلق النفيس من كل شيء('). ولا مـراء أن مثل هذه المعاجم تسهم بشكل جلي في تتميـة الثروة اللغويـة لدى

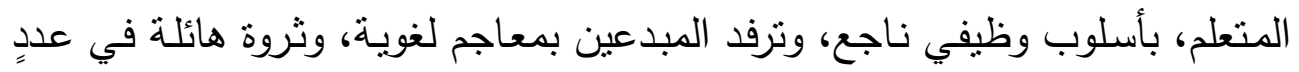

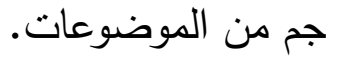

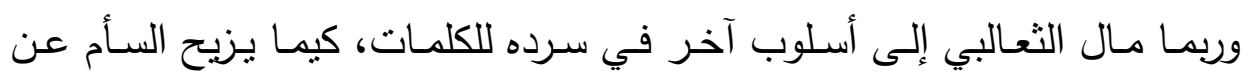

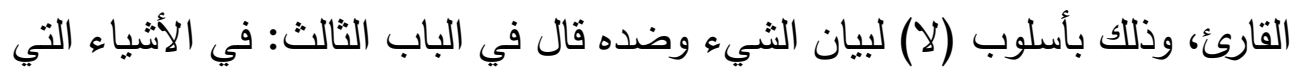
تختلف أسماؤها وأوصافها باختلاف أحوالها:

لا تقال كأس، إلا إذا كان فيها شـراب، وإلا فهي زجاجـة، ولا يقال: مائدة إلا إذا كان عليها طعام، وإلا فهي خِوان. ولا يقال: كوز إلا إذا كانت له عروة، وإلا فهو كوب. ولا يقال: خاتم إلا إذا كان فيه فص، وإلا فهو فَتَخْة (r'). وفي أحايين أخرى ينفى ولا يذكر المعادل. لا يقال للمرأة ظعينة: إلا ما دامت راكبة في الهودج. 
ولا يقال للثوب: حلة إلا إذا كان ثوبين اثثين من جنس واحد(rا'). وأحياناً ينفح المتلقي بباب من الأضداد نافع.

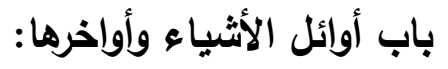

صدر كل شي وغرته أوله، فاتحة الكتاب أوله، ريّق الثباب أوله. ثم يعقبها في

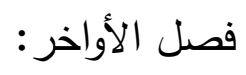

الغلس والغبش: آخر ظلمة الليل. الكيّول: آخر الصف.

وينفحنا بباب آخر من الأضداد، الباب الخـام، في صـغار الأشياء وكبارها، وعظامها، وضخامها.

الغوغاء: صغار الجراد، والفسيل: صغار الثجر •

ثم ينقلك إلى أضدادها في فصل: في الكبير من عدة الأثشياء: الرس البئر الكبيرة،

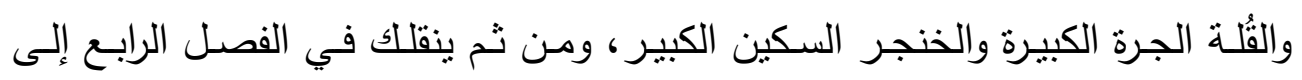

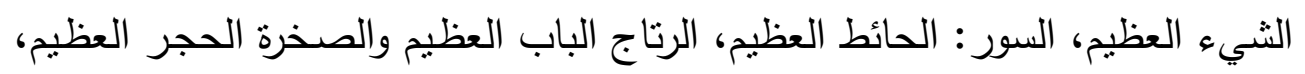

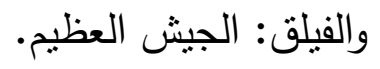

ولدى تعاطي الدارس مـع هذه المعطيات، ينمي ثروته، ويصله الثغالبي بعندياته

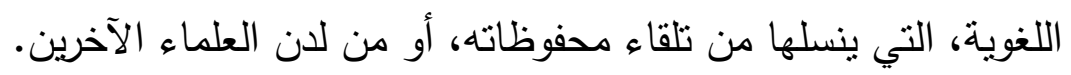
وخصص الباب السادس للطول و القصر.

والسابع في اليبس واللين، والثامن في الثدة والثنديد من الأثباء والتاسع في القلة

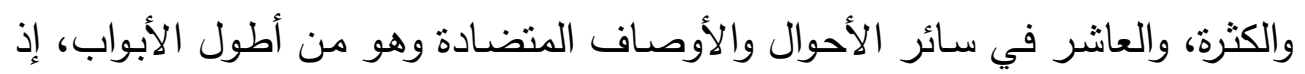
جعله في ثمانية وثلاثثن فصلاً. والحادي عشر في الملء والامتلاء والصفور والخلاء، والثناني عثر في الثيء بين الثيئين، والثالث عشر في الألوان والآثار ، والرابع عشر في أسنان والثان الناس والدواب. 
والخامس عشر في الأصسول والرؤوس والأعضـاء والأطراف وهو أطول الأبواب، إذ جعله في خمسة وستين فصلاً.

منها فصل في تقسيم الثُعر وهو الخامس، قال: الثُعر للإنسان وغيره والمِزْعزيّي

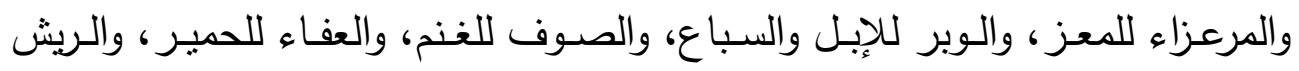

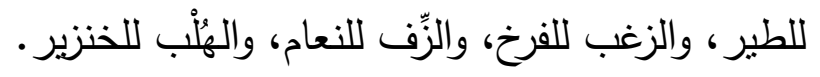
ثم يجعل الفصل السادس في تفصيل شعر الإنسان. العقيقة: الثعر الذي يولد بـ الإنسان، الفروة: شعر معظم الرأس والناصية شعر

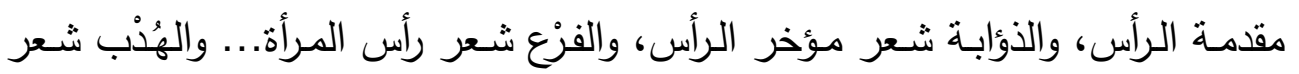

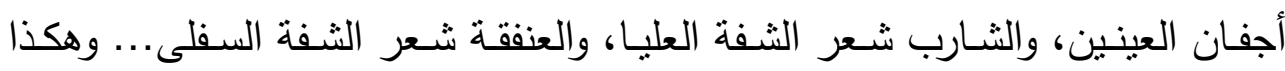
دواليك.

ويأني على تفاصيل جسم الإنسان من محاسن وعيوب.

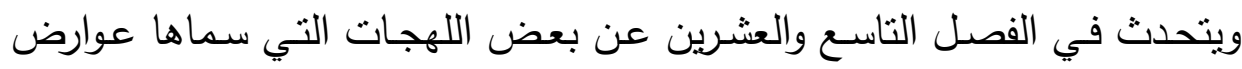

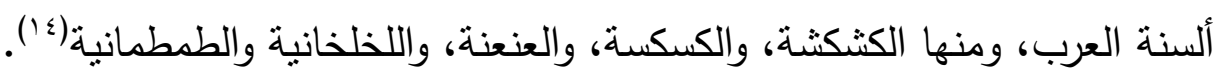
وهكذا ينقلك الثعالبي من علم إلى علم وتلج معه أبواباً متتوعة حتى يفضي بك في آخر المطاف إلى الباب الثلاثين في فنون مختلفة الترتيب في الأسماء والأفعال

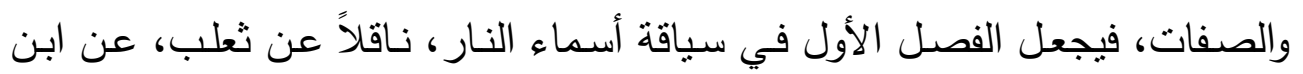

$$
\text { الأعرابي. }
$$

وفي الفصل الثالث: في الدواهي، قال: وقد جمع حمزة من أسمائها ما يزيد على ألى أربعمئة، وذكر أن تكاثر أسماء الدواهي من إحدى الدواهي وذكر منها: نازلة، ونائية ونائة

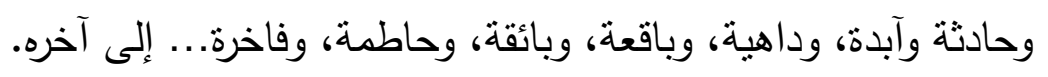
وهذا الفصل مؤشر على أخذ الثعالبي بفكره الترادف في العربية، وتأييدها. 
وينقلنا الثـيخ إلى فصل مـن الأضـداد وهو السـادس عثر الموسوم بـ "تسمية

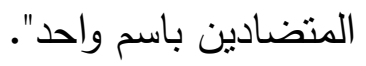
الغريم: المولى والزوج، والبيّع. والوراء يكون خلف وقدام. الصريم: الليل والصبح، والجلل: اليسير والعظيم، والجون الأسود والأبيض(10). ولو رجعنا النظر، وحدقنا في الأبواب والبصائر اللغوية، التي انطوى عليها المعجم

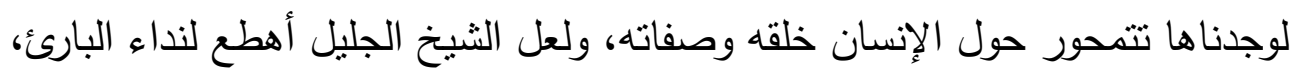

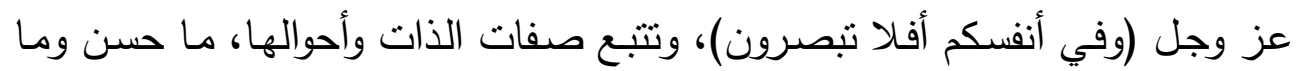
ساء، ثم أعقبها بذكر نعوت الحيوان، ثم التبصر في مخلوقات الهه وعظمته في الآثار العلوية من برق ورعد ومطر وسحاب، والآثار السفلية في الأنهار والجبال والآبار

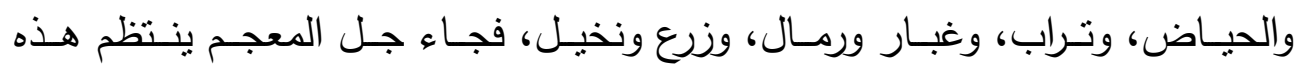
المعطيات، ويتمحور حولها.

ومن الطريف أن الثعالبي جعل الباب التاسع والعشرين: فيما يجري مجرى الموازنة

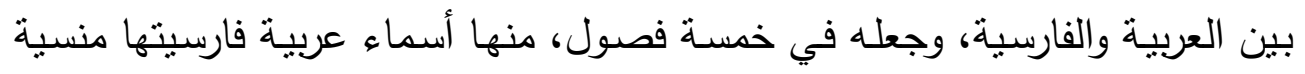
وعربيتها محكية مستعطلة، وفسل يناسبه في أسماء عربية يتعذر وجود فارسية أكثرها

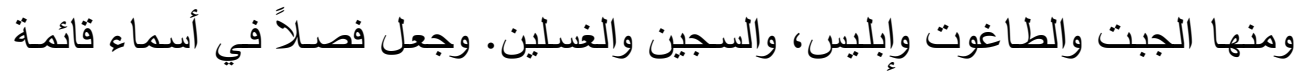

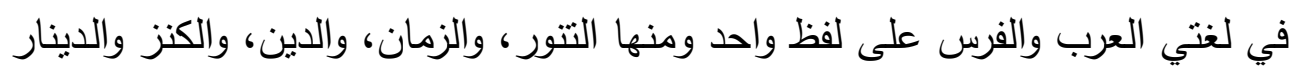

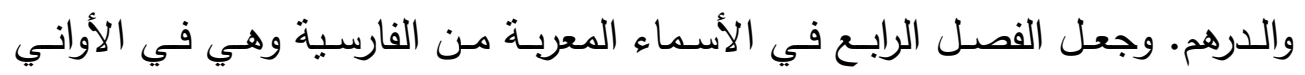

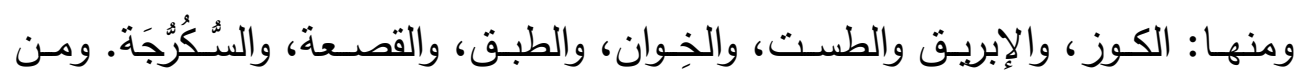

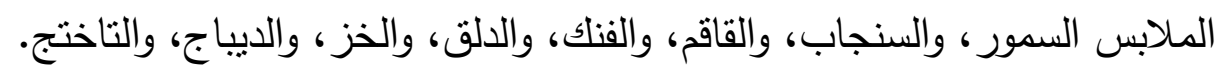
وبعضها من الجواهر منل الياقوت، والبلور . وبعضها من ألوان الخبز مثل السميذ، والدرمك، والجردق، والكعلك وبعضهـا من الرياحين منل: النرجس والبنفسج، والنسرين، والخيري والسوسن، والياسمين، والجلنار . 


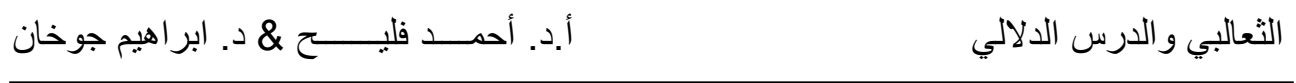

وبعضها من الطيب مثل: المسك، والعنبر ، والكافور ، والصندل، والقرنفل. وفي

كثير من هذه الأسماء تقتضي التحقق، ورجع النظر .

وجعل الفصل الخامس مما نسبه بعض الأئمة إلى اللغة الرومية.

ومنها الفردوس: البستان.

ومنها القسطاس: الميزان.

ومنها السجنجل: المرآة.

والبطاقة والقبان، والاصطرلاب، والقسطرى، والجُهِبذِ والقسطل أي الغبار، والقنطار

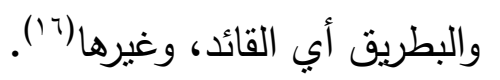

وفي قراءة لهذه المعطيات قد يتبادر إلى الفهم أن الثعالبي كان يعرف الفارسية،

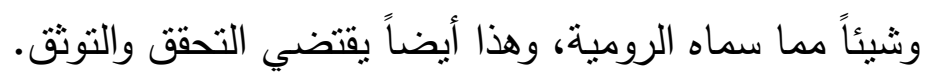

$$
\text { منهج الكتاب وخطته: }
$$

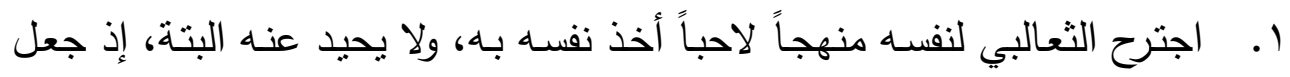

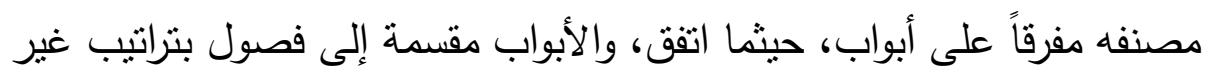

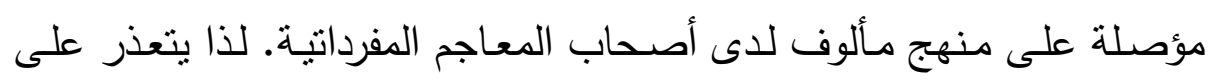

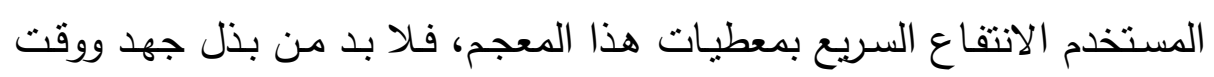
للوصول إلى ضالثه.

r. توكأ على عدد من العلماء السابقين في الرواية، من غير أن يحدد مواقع النقل

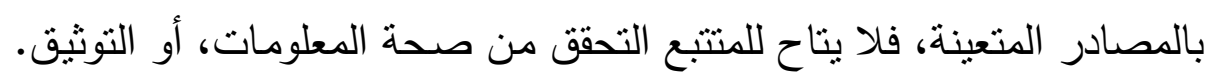

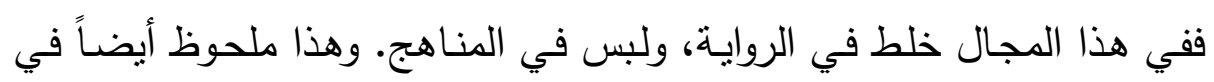
جل أصحاب هذا المذهب المعجي. 
ومن يحدق في كتاب مبادئ اللغة للإسكافي (ت ابكأهـ) يلحظ مثل هذا الخلط

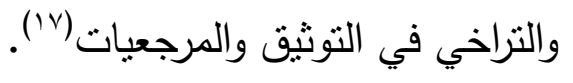

بيد أنه حين يستشهد بالثواهد الثعرية، فإنه في الغالب كان يعزوها إلى قائلها،

$$
\text { وهذا مما يحمد له (1). }
$$

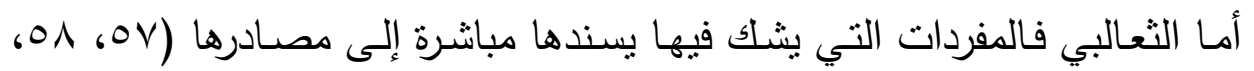

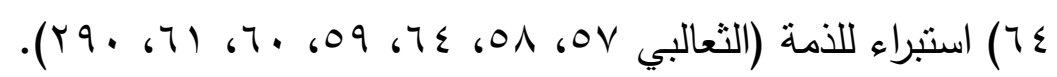

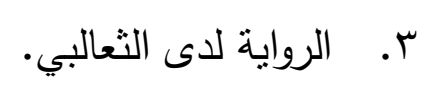

يذكر الثعالبي في بداءة الفصل عمن أخذ أحياناً.

فيقول: عن: الليث وعن الخليل، وعن ثطلب عن ابن الأعرابي، وعن سلمة عن

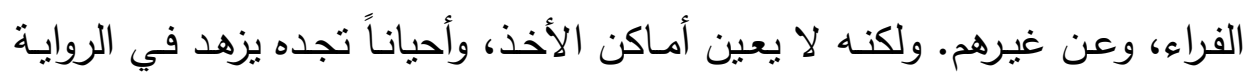

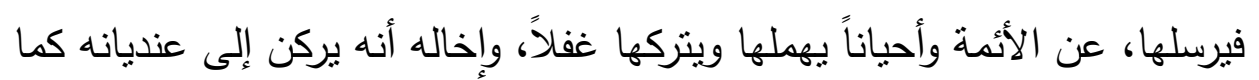

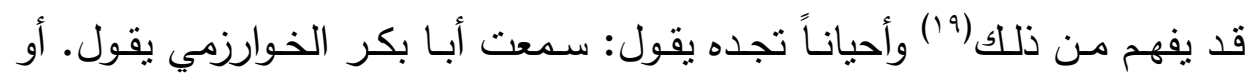
سمعت العرب تقول، أو عن الزجاج، وقال المؤرج، استبراء للأمة. ع. شواهده: جل الثواهد في مطاوي المعجم شعرية، استشهد لعدد من الثعراء في

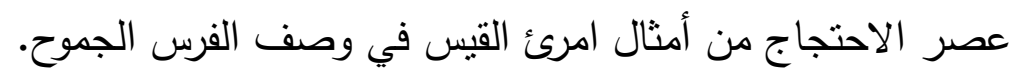

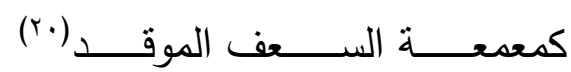

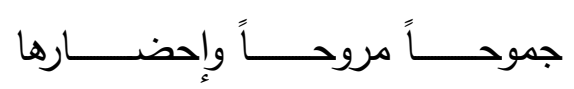

$$
\text { واستشهد بشعر زهير ، وعبيد بن الأبرص والأعشى في قوله في الكساء: }
$$

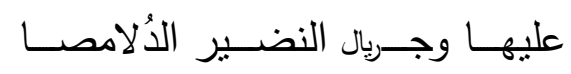
إذا جـردت يومـاً حسـبت خميصــة وقد ينشد لبعض الأعراب: 


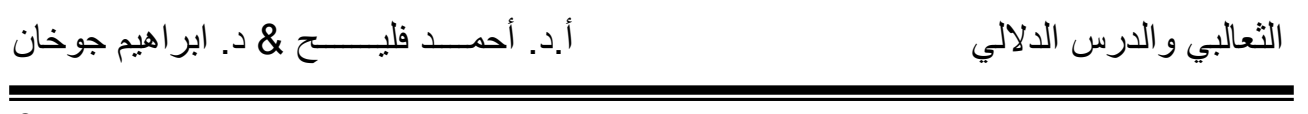

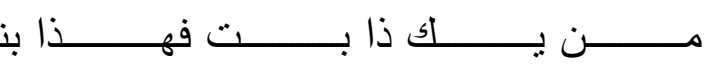

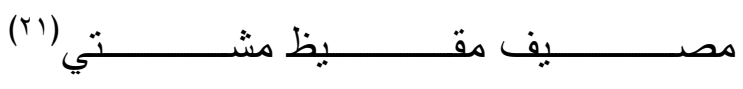

$$
\text { واستتهد للثاعر لبيد بنصف بيت وأحياناً بييت(rr). }
$$

واستتشه للنابغة في الألوان(rr) وفي الغالب يعزو الثعر إلى قائله.

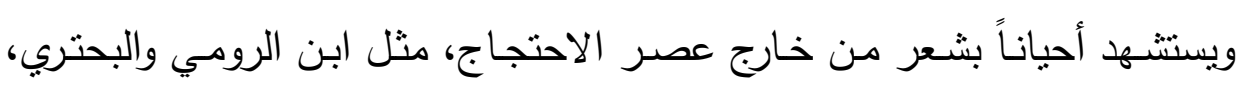

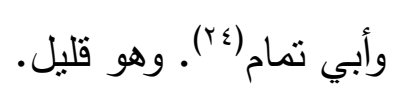

والثنالبي لا يعول على الروايـة بالمشافهة، في جل مروياته، بل ربما كان يأخذ

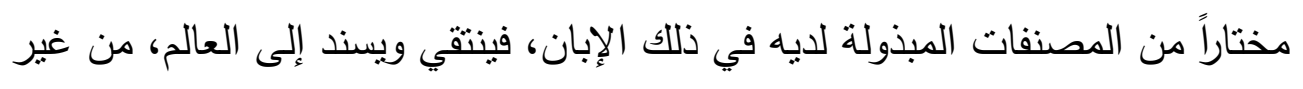
إنشارة توثيقية إلى عنوان المصدر . 


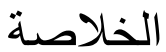

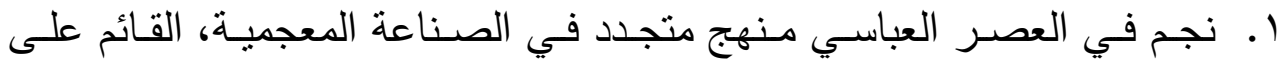

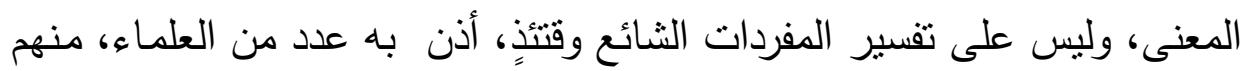
الثنالبي في مصنفه فقه اللغـة وسـر العربيـة، استهدف بمحتوياته، العلمـاء، بلـه الثداة، لتمكين العربية الفصحى في نفوسهم. فهو مصدر ثز يغني الدارس، ويعزز

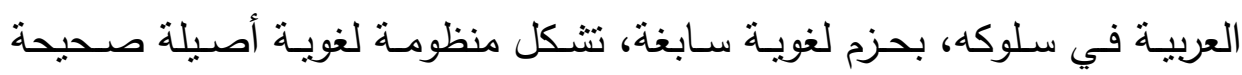

$$
\text { فصيحة، تسعف في رفع السوية وتحسينها. }
$$

r. كتاب فقه اللغة وسر العربية للثعالبي ليس كتاب فقه لغة، على نحو ما ألمحنا في

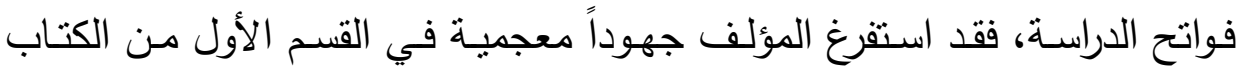

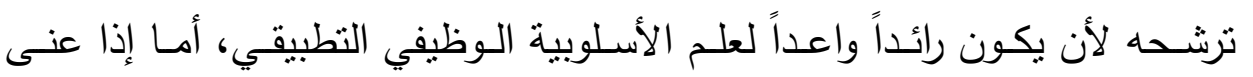

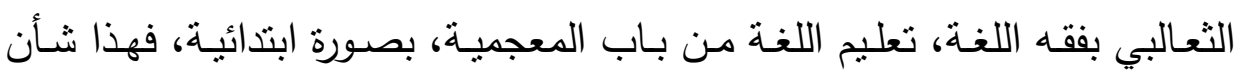
آخر ، ولا ينسجم وأدبيات فقه اللغة.

r. يشير صنيع الثعالبي وأقرانه في هذا الصدد إلى غنى العربية الذي لا ينضب

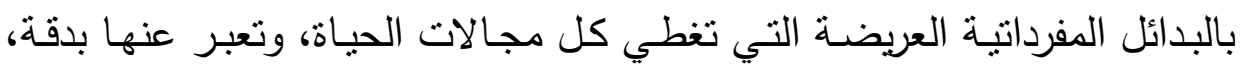

$$
\text { ومن غير تجهم أو تعبس. }
$$

ع . نوجه دعوة إلى الحراص على العربية والغير على سيرتها، للنهوض برسالة إعادة

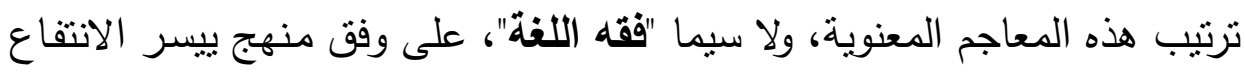

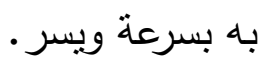

هـ أذن الثعـالبي في معجمـهـ بـبعض الــلالات الحضــارية، فضــلاً عـن الــلالات

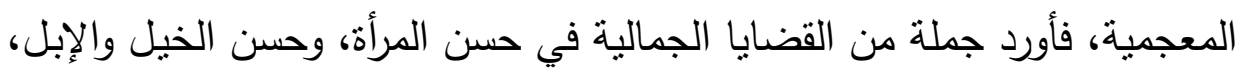

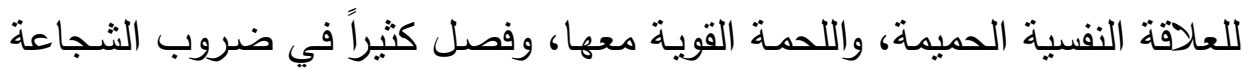
والرجولة التي تشخص قيم عصره. 


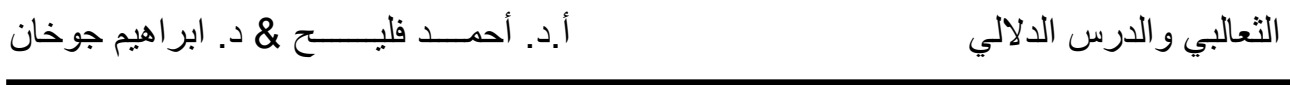

7. ثمة إثنارات إلى بعض اللهجات العربية القديمة، وبعض الأدواء، ومنها السرطان

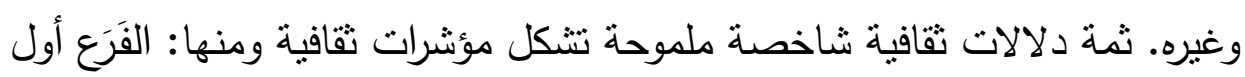

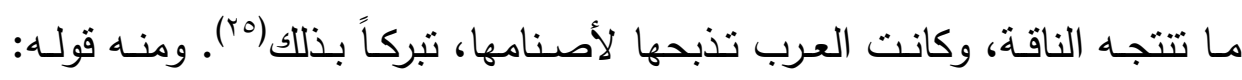

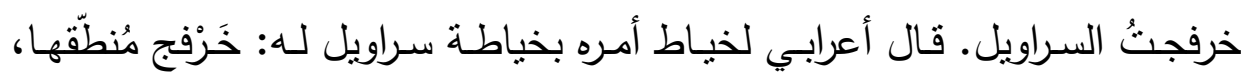

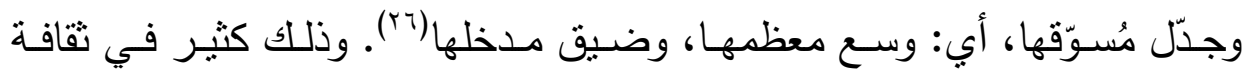
اللباس، والفرش، والأكسية.

وأخيراً لا مندوحة من القول، تطلب الإنصاف، إن جمهرة هذه الألفاظ والتراكيب

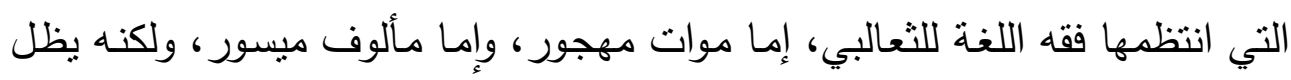
تذكرة وتفعيلاً، للتواصل وتثمير المنجز لاستيعاب الموروث النقافي بأريحية. ومـع هذه الهنـات الهينـات، فـلا نقدر أن نغمط هذا الجهد، في هذه المعلمـة

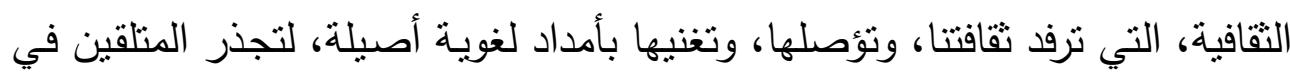
مفاصلها.

والحمد لله أولاً وآخراً 
1. عبد السلام المسدي: قاموس اللسانيات، ص آ ـ.

وينظر : بالمر : علم الدلالة، ترجمة محمد الماشطة، 1.

أحمد محمد قدور : مبادئ اللسانيات، ص ب rV9؛ فوزي الثايب: محاضرات في

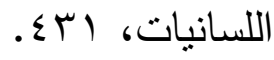

r. حسن ظاظا: كلام العرب، دار النهضة العربية، VII.

r. إبراهيم أنيس: دلالة الألفاظ، • •r.

ع. عبده الراجحي: فقه اللغة في الكتب العربية، سד 1.

0. حسن ظاظا: كلام العرب، ؟ب ا.

ماريوباي: أسس علم اللغة، ترجمة د. أحمد مختار عمر، عالم الكتب، صع ع.

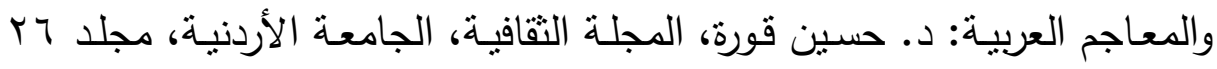

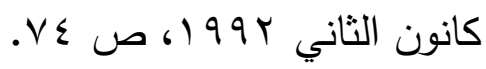

T. علي عبد الواحد وافي: فقه اللغة، دار نهضة مصر، القاهرة، INIX. علي عبد الواحد وافي: علم اللغة، دار نهضة مصر، طبعة سابعة، ؟ V V

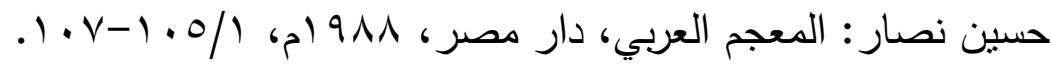
V. ماريوباي: أسس علم اللغة، ص هـ. ^. بول كراوس: فقه اللغة للثعالبي، المقدمة، ص V V. 9. الثعالبي: فقه اللغة وسر العربية، (r.

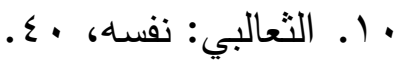




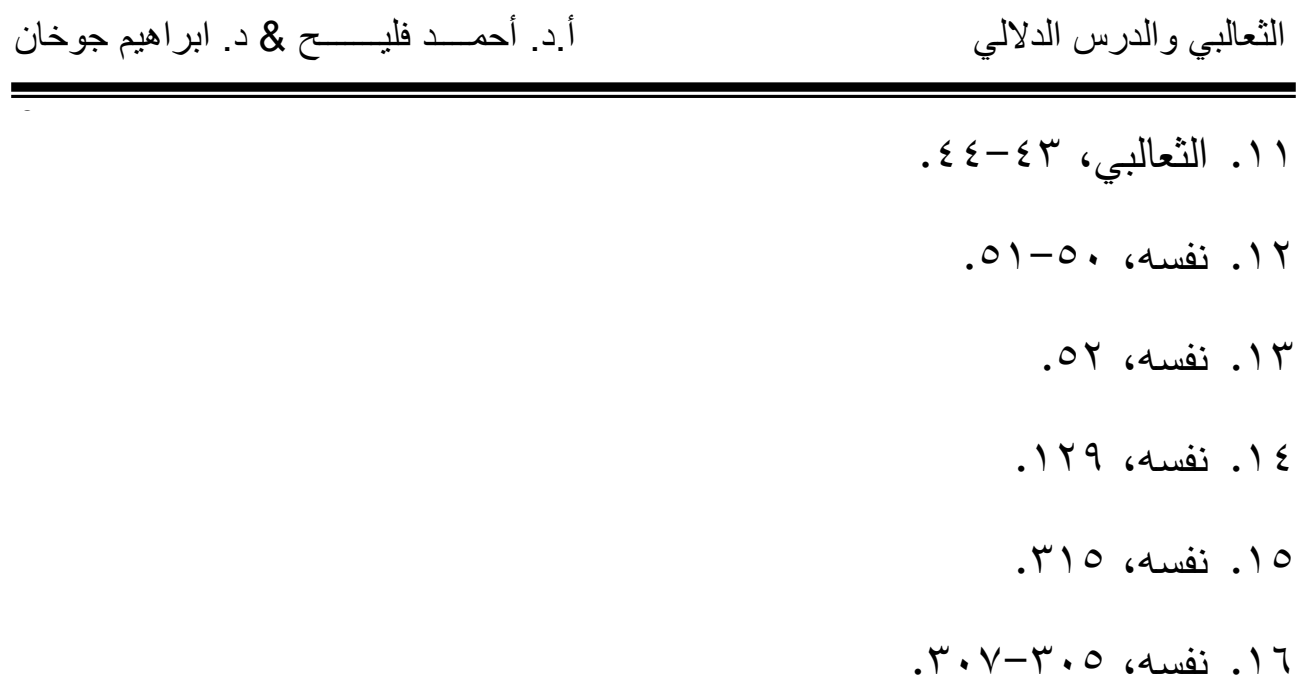

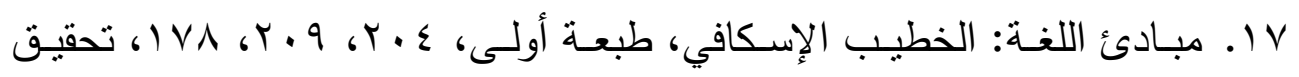
د. يحيى عبابنة و د. عبد القادر الخليل.

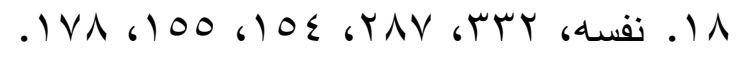

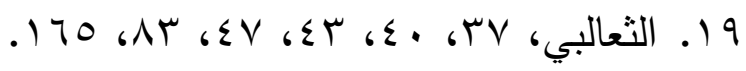

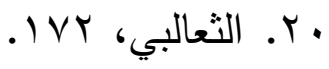

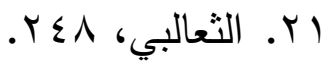

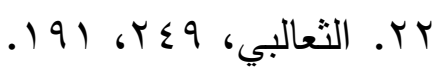

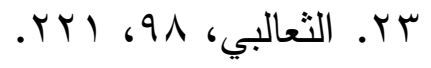

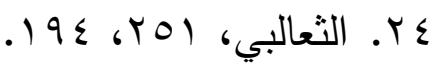
OY. نفسه، 00. T Y. نفسه، 